\title{
Evaluation of the adherence to antidiabetic medications among Iraqi patients with T2DM using the Iraqi antidiabetic medication adherence scale (IADMAS)
}

\author{
Saad Abdulrahman Hussain ${ }^{1}$ (D) Haydar Fakhri Al-Tukmagi² (D), Zainab Saad Abdulrahman ${ }^{3}$ (D), \\ Maryem Maythem Sadeq ${ }^{1}$ (D), Dania Natheer Hashim ${ }^{10}$, Rand Sabah Kadhim ${ }^{1}$, \\ Mohammed Mahdi Muayad Kubba ${ }^{4}$ (1), Dur Haydar Al-Tukmagi ${ }^{4}$ (I) \\ 'Al-Rafidain University College, Faculty of Pharmacy, Baghdad, Iraq \\ ${ }^{2}$ Baghdad College of Medical Sciences, Department of Pharmacy, Baghdad, Iraq \\ ${ }^{3} \mathrm{Al}-$ Kindy Teaching Hospital, Department of Clinical Pharmacy, Baghdad, Iraq \\ ${ }^{4}$ Shaheed Al-Sadr Teaching Hospital, Baghdad, Iraq
}

ORCID IDs of the authors: S.A.H. 0000-0002-1909-417X; H.F.A. 0000-0002-4174-6074; Z.S.A. 0000-0002-7644-8093; M.M.S. 0000-0002-3919-2885; D.N.H. 0000-0001-6632-6431; R.S.K. 0000-0002-1733-6382; M.M.M.K. 0000-0001-6677-0735; D.H.A. 0000-0002-6569-5275

Cite this article as: : Hussain, S. A., Al-Tukmagi, H. F., Abdulrahman, Z. S., Sadeq, M. M., Hashim, D. N., Kahdhim, R. S.... Al-Tugmagi, D. H. (2021). Evaluation of the adherence to antidiabetic medications among Iraqi patients with T2DM using the Iraqi antidiabetic medication adherence scale (IADMAS). Istanbul Journal of Pharmacy, 51 (3), 307-312.

\section{ABSTRACT}

Background and Aims: Management of diabetes is a multifactorial process, and adherence to treatment programs plays a role in glycemic control. The present study evaluates the adherence rate to the antidiabetic medications with a newly developed scale and patients' HbA1c levels among Iraqi patients with type-2 diabetes.

Methods: A cross-sectional study among adult patients receiving diabetic care in public and private healthcare settings within Baghdad City was conducted. The medication adherence was evaluated using the Iraqi Antidiabetic Medication Adherence Scale (IADMAS) to determine the factors associated with non-adherence to anti-diabetic medications. Glycated hemoglobin (HbA1c) levels of the participants were used as an indicator of glycemic status.

Results: The outcome measures include the comparison between glycemic status and the claims of antidiabetic medication adherence of patients with T2DM, in addition to the expected benefits to clinical practice. A total of 442 patients with type 2 diabetes participated in the study and responded by completing the given questionnaire (response rate: $96.1 \%$ ). The prevalence of non-adherence to medication was reported to be no more than $30 \%$. Adherence based on $\mathrm{HbA} 1 \mathrm{c}$ values reflected a high false-positive value of adherence with an extremely high true negative value. The adherence of Iraqi patients to their medications demonstrated a high negative predictive value (0.905) and a high sensitivity (0.928) with low specificity (0.156) values.

Conclusion: The use of IADMAS in this study failed to confirm the consistency between the apparent claims of adherence to anti-diabetic medications and the $\mathrm{HbA1c}$ value as a marker of glycemic control.

Keywords: T2DM, antidiabetic medications, patient adherence, IADMAS

Address for Correspondence:

Saad Abdulrahman HUSSAIN, e-mail: saad.hussain@ruc.edu.iq

This work is licensed under a Creative Commons Attribution 4.0 International License. 


\section{INTRODUCTION}

Diabetes mellitus (DM) is a common chronic metabolic condition that has been on the rise in recent years (Ogurtsova et al, 2017). Based on its pathophysiology, diabetes causes a variety of acute and chronic health problems that, if not adequately managed, can result in severe morbidity and mortality (Stolar, 2010; Bertoni, Krop, Anderson, \& Brancat, 2002). In terms of epidemiology, the number of adults diagnosed with diabetes has risen rapidly, from 108 million cases in 2000 to 422 million cases in 2014. Most patients are unconcerned about their health issues, and many do not undergo treatment (Chan, 2017). Deaths from diabetes are anticipated to rise, and diabetes may become one of the top ten causes of death by 2030 (Sarwar et al., 2010). Type 1 diabetes mellitus (T1DM) and type 2 diabetes mellitus (T2DM) are the two main kinds of diabetes mellitus (DM). T1DM is caused by a lack of insulin production and is usually linked to an autoimmune illness, whereas T2DM is caused by insufficient insulin production and/or resistance of target tissues to its action and is the most prevalent type of diabetes worldwide (ADA, 2020; Kaiser, Zhang, \& Van der Pluijm et al, 2018). T2DM is caused by a number of risk factors, including a lack of physical activity, poor dietary habits, and smoking (among many others), all of which raise the risk of getting the disease (Bi et al., 2012). As a result, the treatment strategies for T2DM include both medication and lifestyle changes. Poor adherence to T2DM treatment guidelines might result in an adverse response and serious comorbidities such as gangrene, nephropathy, retinopathy, neuropathy, and stroke (Forbes \& Cooper, 2013), while proper adherence to the treatment program is crucial and required to get the best possible treatmentrelated outcomes (Chaudhury et al., 2017). Unfortunately, poor adherence is a widespread issue among patients with T2DM around the world (Polonsky \& Henry, 2016), which may be linked to poor glycemic control and higher treatment costs as a result of greater use of healthcare resources (Egede, Gebregziabher, Echols, \& Lynch, 2014; Egede et al., 2012). Currently, a variety of practical and accurate patient-reported measures are frequently used to assess treatment adherence among diabetic patients (Stirratt et al, 2015; Capoccia, Odegard, \& Letassy, 2016). The vast majority of currently valid and widely used tools to assess antidiabetic medication adherence, such as the Medication Adherence Questionnaire (MAQ), the Morisky Medication Adherence Scale-eight items (MMAS-8), the Medication Adherence Rating Scale, and the Adherence to Refills and Medication Scale, are not specific enough to achieve the ideal targets because they are not primarily used for assessing antidiabetic medication adherence (Nguyen, Caze, \& Cottrell, 2014). Although most of the adopted instruments are designed to assess medication adherence in patients in affluent nations, only a few scales, such as the Malaysian Medication Adherence Scale (MALMAS), are designed to assess adherence to anti-diabetic drugs in developing countries (Chung, Chua, Lai, \& Morisky, 2015). Because of the significant differences in cultures and beliefs in this regard, it is acknowledged that community-related personal characteristics and cultural beliefs can significantly influence the adherence of patients with T2DM to their treatment protocols (Chia, Schlenk, \& DunbarJacob, 2006). This will not ensure proper implication of an em- pirical formula for evaluating medication adherence among Iraqi patients.

The aim of this study is to examine adherence to antidiabetic drugs in Iraqi patients with T2DM using a locally designed modified scale produced by Mikhael et al in 2019 (Mikhael, Hussain, Shawky, \& Hassali, 2019) and HbA1c values.

\section{METHODS}

\section{Patient selection and study design}

In this cross-sectional study, a sample of 460 patients (>18 years of age) previously diagnosed with T2DM were randomly recruited from public and private clinical settings within the Baghdad City area from August 2019 to April 2020. They had previously been on antidiabetic medications for at least 6 months before inclusion in this study. Only 442 patients successfully filled the questionnaire, and their responses were included in the study. The exclusion criteria included T2DM patients with associated comorbidities such as impaired renal function, cognitive disorder, depression, and pregnancy. Before inclusion, all patients were clinically assessed to exclude anyone with suspected but undiagnosed depression (Whooley, Avins, Miranda, \& Browner, 1997).

\section{Ethical approval}

The research protocol was evaluated and ethically approved by the Local Research Ethics Committee for Medical Studies, Faculty of Pharmacy, Al-Rafidain University College (REC: 4/2019). All the enrolled patients were required to provide verbal consent before participation in the study.

\section{Assessment and outcome evaluation}

All the recruited patients were interviewed by the researchers to thoroughly explain the purpose of the study and details of the protocol. Only those who provided their informed consent were requested to complete a self-administered questionnaire based on the locally designed and validated form, and the Iraqi Antidiabetic Medication Adherence 5 Scale (IADMAS) (Mikhael et al, 2019). The IADMAS has eight items in total, three of which were used to assess medication-taking behavior directly by providing five responses: (1) always (daily), (2) often, (3) occasionally, (4) seldom, and (5) never. The remaining five items were utilized to determine the cause of non-adherence by providing a binary response of "Yes" or "No."The questionnaire was presented to patients with unsatisfactory educational levels and those with visual impairment via a face-to-face interview with the researchers. The participants needed approximately 5-10 min to complete the questionnaire. HbA1c values less than 7 were considered to have good glycemic control (Grant \& Kirkman, 2015).The association between glycemic control and adherence to antidiabetic medications was utilized to measure true positive (TP) results (patients who are non-adherent to their treatment and have poor glycemic control), false positive (FP) results (patients with poor glycemic control despite being adherent to their treatment), true negative (TN) results (patients with good glycemic control and good medication adherence), and false-negative (FN) results (patients with good glycemic control despite being non-adherent to their treatment). Specificity and sensitivity, as well as positive 
Hussain et al. Evaluation of the adherence to antidiabetic medications among Iraqi patients with T2DM using the Iraqi antidiabetic medication adherence scale (IADMAS)

and negative predictive values of the IADMAS outcomes, were measured using the following equations:

Positive predictive value $=100 \% \mathrm{TP} /(\mathrm{TP}+\mathrm{FP})$

Negative predictive value $=\mathrm{TN} /(\mathrm{TN}+\mathrm{FN}) \times 100 \%$

Sensitivity $=\mathrm{TP} /(\mathrm{TP}+\mathrm{FN}) \times 100 \%$

Specificity $=\mathrm{TN} /(\mathrm{TN}+\mathrm{FP}) \times 100 \%$

The reliability of the scale was evaluated by test-retest on 40 patients with a Cronbach-a value of 0.87 .

\section{Statistical analysis}

Data input and analysis were done using the Statistical Package for the Social Sciences (SPSS) V.24. Categorical variables were presented as percentages and frequencies, while mean and SD was used to present continuous variables. The Kolmogorov-Smirnov test was used to test the normal distribution of continuous variables. The Mann-Whitney $U$ test was used to test the mean difference between continuous variables when applicable. The P values below 0.05 were considered for significant differences between variables.

\section{RESULTS}

A total of 460 participants were recruited to participate in the present study and 442 of them responded by completing the given questionnaire (response rate: 96.1\%). Demographic and clinical details of the participants are presented in Table 1. The male gender represents $56 \%$ of the participants. The other characteristics of the participants show that $76.6 \%$ of them are positive smokers and $71.3 \%$ of them have a positive family history of T2DM and only $22 \%$ of them are physically active. However, $63.3 \%$ of the participants followed a dietary restriction program. Table 1 also shows that $82 \%$ of the participants followed a treatment program that included oral antidiabetic medications only. In Table 2, many participants stated they never missed or changed the doses of their medication, and never changed the timing of their doses (56\%-75\%) but only a small percentage actually practiced such actions (2\%-15\%). Regarding of the adherence of participants to their medications in different conditions, Table 3 indicates that 99.3\% take their medications with them when they are away from home; and 97\% did not stop taking their medications without medical consultation about the awareness of adverse effects. Ninety-seven percent did not

Table 1. Demographic and characteristic data of the participants $(n=442)$.

\begin{tabular}{|c|c|}
\hline Parameter & Value \\
\hline Age (years), mean $\pm S D$ (range) & $52.55 \pm 12.31(24-80)$ \\
\hline \multicolumn{2}{|l|}{ Gender $\mathrm{n}(\%)$} \\
\hline Male & $247(56)$ \\
\hline Female & $195(44)$ \\
\hline Body mass index $\left(\mathrm{kg} / \mathrm{m}^{2}\right)$, mean $\pm \mathrm{SD}$ (range) & $28.47 \pm 4.81(17-44)$ \\
\hline Positive cigarette smoking, $\mathrm{n}(\%)$ & $339(76.6)$ \\
\hline Positive family history, $\mathrm{n}(\%)$ & $315(71.33)$ \\
\hline Positive physical activity, $\mathrm{n}(\%)$ & $97(22)$ \\
\hline Positive Dietary restriction, $\mathrm{n}(\%)$ & $280(63.33)$ \\
\hline Duration of DM (year), mean \pm SD (range) & $8.62 \pm 4.66(1-23)$ \\
\hline Number of prescribed medications, mean $\pm S D$ (range) & $1.81 \pm 0.94(1-5)$ \\
\hline \multicolumn{2}{|l|}{ Type of medication, $\mathrm{n}(\%)$} \\
\hline Oral & $362(82)$ \\
\hline Injectable & $50(11.3)$ \\
\hline Combination & $30(6.7)$ \\
\hline Duration on treatment (year), mean $\pm S D$ (range) & $6.67 \pm 3.97(1-20)$ \\
\hline Glycosylated hemoglobin (\%), mean \pm SD (range) & $7.83 \pm 1.1(5-10)$ \\
\hline
\end{tabular}

Table 2. Adherence of patients with T2DM to the dosing of anti-diabetic medications ( $n=442)$.

\begin{tabular}{|lcccc|}
\hline Self-Action $n(\%)$ & Rarely & Sometimes & Never & Always \\
\hline Missing drug doses & $171(38.7)$ & $19(4)$ & $248(56)$ & $6(1.3)$ \\
Change drug doses & $71(16)$ & $21(4.7)$ & $332(75.3)$ & $18(4)$ \\
Change the timing of drug doses & $88(20)$ & $45(10)$ & $297(67.3)$ & $12(2.7)$ \\
\hline
\end{tabular}


Table 3. Diabetic patients' adherence to their medications in various conditions ( $n=442)$.

\begin{tabular}{|lcc|}
\hline Question & Yes & No \\
\hline $\begin{array}{l}\text { Did you take your medication(s) with you when you are away from home? } \\
\text { Did you stop taking your medication (s) without consulting your physician because of } \\
\text { medication side effects? }\end{array}$ & $419(99.3)$ & $12(2.7)$ \\
$\begin{array}{l}\text { Did you take less of your medication (s) without consulting a physician because you } \\
\text { feel better? }\end{array}$ & $13(3)$ \\
$\begin{array}{l}\text { During sick days, did you take less of your medication(s) without consulting a } \\
\text { physician due to reduced appetite? } \\
\begin{array}{l}\text { Did you take less of your medication(s) without consulting a physician because of a } \\
\text { high medication cost? }\end{array}\end{array}$ & $23(5.3)$ \\
\hline
\end{tabular}

Table 4. TP, TN, FP, and FN values for IADMAS calculated based on HbA1c values ( $n=442)$.

\begin{tabular}{|lcc|}
\hline Parameter & Low Adherence $n(\%)$ & Moderate and High Adherence $n(\%)$ \\
\hline Poor glycemic control, HbA1c $\geq 7 \%$ & $77(20.2) \mathrm{TP}$ & $303(79.8) \mathrm{FP}$ \\
\hline Good glycemic control, HbA1c $<7 \%$ & $56(90.5) \mathrm{TN}$ & $6(9.5) \mathrm{FN}$ \\
\hline FN, false negative; FP, false positive; IADMAS, Iraqi Anti-Diabetic Medication Adherence Scale; MAQ, TN, true negative; TP, true positive. \\
\hline
\end{tabular}

\section{Table 5. Specificity, sensitivity, as well as positive and negative predictive values for the IADMAS in the included patients with T2DM ( $n=442)$.}

\begin{tabular}{|ll|}
\hline Parameter & Value \\
\hline Positive Predictive Value & 0.202 \\
Negative Predictive Value & 0.905 \\
Sensitivity & 0.928 \\
Specificity & 0.156 \\
\hline
\end{tabular}

consume fewer medications because they felt better, and 94\% did not consume fewer medications due to a reduced appetite during sick days. Additionally, only 22\% of the participants showed the tendency to consume fewer antidiabetic medications than indicated by their physician due to the high-cost burden. Table 4 indicates that the calculation of adherence based on the $\mathrm{HbA} 1 \mathrm{c}$ values reflected a high false-positive value (79.8\%) of adherence with an extremely high true negative value (90.5\%). Table 5 shows that using IADMAS to screen the adherence of Iraqi T2DM patients to their medications demonstrated a high negative predictive value (0.905) and high sensitivity (0.928) with low specificity (0.156) values.

\section{DISCUSSION}

In addition to the outcomes of adequate cure and disease control, antidiabetic medications can be used to improve the quality of life and limit the progression of the disease. Accordingly, patient compliance with the treatment protocols supports the success of the treatment plan (Wilke et al., 2013). Poor adherence to prescribed diabetes medications has been identified as a major source of suboptimal T2DM management and its asso- ciated complications (Ho et al., 2006). The pattern of changes in the scores that evaluate adherence to antidiabetic medications from variations in parameter values was highly expected based on theoretical considerations. For instance, for an acceptable rate of adherence, the variation to label patients as "adherent" can significantly influence the scores of adherence measures (Sodihardjo-Yuen, van Dijk, Wensing, De Smet, \& Teichert, 2017). Recently, a modified formula (IADMAS) was designed and validated for the evaluation of T2DM patients' adherence to their medications in the Iraqi community (Mikhael et al., 2019). Although IADMAS shows acceptable internal consistency, stable reliability, and good concurrent validity, sensitivity, and specificity compared with other internationally developed scales, its local large-scale application to evaluate adherence of Iraqi patients to their antidiabetic medications is not tried and may reflect conflicting results, especially when the expected outcomes are not compatible with the biochemical evidence of glycemic control (HbA1c) (de Vries McClintock, Morales, Small, \& Bogner, 2016). In the present study, more than one-third of the participants can be ranked as poor in relation to their adherence in taking anti-diabetic medications. Although this finding could indicate that diabetic patients pay insufficient attention to their health, it could also indicate limitations in the diabetes care program or healthcare services provided in healthcare settings, as well as poor patient counseling on the importance of strict adherence to anti-diabetic medications. Moreover, the reported level of non-adherence seems to be an underestimate since it is based on patient self-reports which usually overestimate patient adherence levels. Similar findings were reported by Ahmad et al. who showed that $53 \%$ of their respondents were non-adherent to medication, in addition to the finding of Abebe et al. (2014) in Ethiopia which indicated the prevalence of 54.1\% (Ahmad, Ramli, Islahudin, \& Paraidathathu, 2013). 
However, lower rates of non-adherence have been reported in Uganda (16.7\%) (Bagonza, Rutebemberwa, \& Bazeyo, 2015; Abebe, Berhane, \& Worku, 2014). This difference in adherence rates could be due to the differences in the healthcare services, socio-economic status, and scales used for the evaluation of adherence across the study settings. The present study indicated a weak but significant inverse correlation between $\mathrm{HbA} 1 \mathrm{c}$ values and the total IADMAS scores of the patients; meanwhile, all subscales of IADMAS had a significant inverse correlation with $\mathrm{HbA1c}$. Furthermore, adherent patients were presented with significantly higher mean $\mathrm{HbA1c}$ levels than those who were non-adherent. Based on this variable $(\mathrm{HbA} 1 \mathrm{c})$, this finding did not confirm the concurrent validity of the IADMAS, and it conflicted with other studies that reported a positive association between medication adherence and glycemic control (Krapek et al., 2004; Schectman, Nadkarni, \& Voss, 2002). Furthermore, the current study found that the IADMAS had acceptable sensitivity but low specificity; this result was nearly universal with most self-reporting approaches used to assess patient adherence to prescribed medications (Lingam \& Scott, 2002). This may be attributed to the bias associated with social desirability which may result from the face-to-face interview method of administering the questionnaire to many patients (Del Brutto, \& Mera, 2016). Besides, social desirability is highly different among cultures and appears to be significantly involved in developing countries such as Iraq (Heissam, Abuamer, \& El-Dahshan, 2015). This study had some limitations, including the use of convenience consecutive sampling, which may lead to selection bias since not all type T2DM patients recruited from the out-patient settings will have had clinical follow-up during the recruitment process. Accordingly, the interpretation of outcomes in terms of generalizability should be cautiously performed. Additionally, the predicted low specificity of the IADMAS in the current study can be due to the limitations of consistent sampling during recruitment (Aminde et al., 2019; Musenge, Michelo, Mudenda, \& Manankov, 2016). Meanwhile, inadequate sample size and recruitment from inconsistent healthcare institutions could be one of the major limitations of the present study. Furthermore, the IADMAS was only validated for patients with T2DM, and further studies are needed to confirm its validity among patients with other types of diabetes.

\section{CONCLUSION}

Although IADMAS is a reliable and valid tool for assessment of adherence to antidiabetic medications, its application in this study failed to confirm the consistency between the apparent claims of adherence to antidiabetic medications and the $\mathrm{HbA} 1 \mathrm{c}$ value as a marker of glycemic control.

Peer-review: Externally peer-reviewed.

Ethics Committee Approval: The study was approved by the Local Research Ethics Committee for Medical Studies, Faculty of Pharmacy, Al-Rafidain University College (REC: 4/2019).

Informed Consent: Written consent was obtained from the participants.

Author Contributions: Conception/Design of Study- S.A.H., H.F.A., Z.S.A.; Data Acquisition- M.M.S., D.N.H., R.S.K., M.M.M.K., D.H.A.; Data
Analysis/Interpretation- S.A.H., Z.S.A.; Drafting Manuscript- H.F.A. M.M.S.; Critical Revision of Manuscript- S.A.H.; Final Approval and ACcountability- S.A.H., H.F.A., Z.S.A., M.M.S., D.N.H., R.S.K., M.M.M.K., D.H.A.

Conflict of Interest: The authors have no conflict of interest to declare.

Financial Disclosure: Authors declared no financial support.

Acknowledgement: The authors thank Al-Rafidain University College for supporting the project.

\section{REFERENCES}

- $\quad$ Abebe, S. M., Berhane, Y. \& Worku, A. (2014). Barriers to diabetes medication adherence in North West Ethiopia. SpringerPlus, 3(1), 195. https://doi:10.1186/2193-1801-3-195

- $\quad$ Ahmad, N. S., Ramli, A., Islahudin, F. \& Paraidathathu, T. (2013). Medication adherence in patients with type 2 diabetes mellitus treated at primary health clinics in Malaysia. Patient Preference and Adherence, 7, 525-530. https://doi:10.2147/PPA.S44698

- American Diabetes Association. (2020). Classification and diagnosis of diabetes: Standards of Medical Care in Diabetes-2020. Diabetes Care, 43(Suppl. 1), S14-S31. https://doi:10.2337/dc20-S002

- Aminde, L. N., Tindong, M., Ngwasiri, C. A., Aminde, J. A., Njim, T., Fondong, A. A., \& Takah, N. F. (2019). Adherence to antidiabetic medication and factors associated with non-adherence among patients with type-2 diabetes mellitus in two regional hospitals in Cameroon. BMC Endocrine Disorders, 19(1), 35. https:// doi:10.1186/s12902-019-0360-9

- $\quad$ Bagonza, J., Rutebemberwa, E. \& Bazeyo, W. (2015). Adherence to anti-diabetic medication among patients with diabetes in eastern Uganda; a cross sectional study. BMC Health Services Research, 15(1), 168. https://doi:10.1186/s12913-015-0820-5

Bertoni, A. G., Krop, J. S., Anderson, G. F. \& Brancati, F. L. (2002). Diabetes-related morbidity and mortality in a national sample of U.S. elders. Diabetes Care, 25(3), 471-475. https://doi:10.2337/diacare.25.3.471

Bi, Y., Wang, T., Xu, M., Xu, Y., Li, M., Lu, J. ....Ning, G. (2012). Advanced research on risk factors of type 2 diabetes. Diabetes Metabolism Research and Reviews, 28(Suppl. 2), 32-39. https:// doi:10.1002/dmrr.2352

- Capoccia, K., Odegard, P. S. \& Letassy, N. (2016). Medication adherence with diabetes medication: a systematic review of the literature. The Diabetes Educator, 42(1), 34-71. https:// doi:10.1177/0145721715619038

- Chan, M. (2017). Obesity and diabetes: the slow-motion disaster. Milbank Quarterly, 95(1), 11-14. https://doi:10.1111/1468-0009.12238

- Chaudhury, A., Duvoor, C., Reddy Dendi, V. S., Kraleti, S., Chada, A., Ravilla, R. ... Mirza, W. (2017). Clinical review of antidiabetic drugs: Implications for type 2 diabetes mellitus management. Frontiers in Endocrinology, 8, 6. https://doi:10.3389/fendo.2017.00006

- Chia, L. R., Schlenk, E. A. \& Dunbar-Jacob, J. (2006). Effect of personal and cultural beliefs on medication adherence in the elderly. Drugs \& Aging, 23(3), 191-202. https://doi:10.2165/00002512-20062303000002

- $\quad$ Chung, W. W., Chua, S. S., Lai, P. S. M. \& Morisky, D. (2015). The Malaysian Medication Adherence Scale (MALMAS): concurrent validity using a clinical measure among people with type 2 diabetes in Malaysia. PLoS One, 10(4), e0124275. https://doi:10.1371/journal. pone.0124275

de Vries McClintock, H. F., Morales, K. H., Small, D. S. \& Bogner, H. R. (2016). Patterns of adherence to oral hypoglycemic agents and glucose control among primary care patients with type 2 diabetes. Behavioral Medicine, 42(2), 63-71. https://doi:10.1080/089642 89.2014.904767 
- $\quad$ Del Brutto, O. H., \& Mera, R. M. (2016). The importance of people compliance (social desirability bias) in the assessment of epilepsy prevalence in rural areas of developing countries. Results of the Atahualpa Project. Epilepsia, 57(12), e221-e224. https:// doi:10.1111/epi.13594

- Egede, L. E., Gebregziabher, M., Dismuke, C. E., Lynch, C. P., Axon, R. N., Zhao, Y. ... Mauldin P. D. (2012). Medication nonadherence in diabetes: longitudinal effects on costs and potential cost savings from improvement. Diabetes Care, 35(Suppl. 1), 2533-2539. https://doi:10.2337/dc12-0572

- $\quad$ Egede, L. E., Gebregziabher, M., Echols, C. \& Lynch, C. P. (2014). Longitudinal effects of medication nonadherence on glycemic control. Annals of Pharmacotherapy, 48(5), 562-570. https:// doi:10.1177/1060028014526362

- Forbes, J. M. \& Cooper, M. E. (2013). Mechanisms of diabetic complications. Physiological Reviews, 93(1), 137-188. https:// doi:10.1152/physrev.00045.2011

- Grant, R. W. \& Kirkman, M. S. (2015). Trends in the evidence level for the American Diabetes Association's "Standards of Medical Care in Diabetes" from 2005 to 2014. Diabetes Care, 38(1), 6-8. https://doi:10.2337/dc14-2142

- Heissam, K., Abuamer, Z., \&El-Dahshan, N. (2015). Patterns and obstacles to oral antidiabetic medications adherence among type 2 diabetics in Ismailia, Egypt: a cross section study. Pan African Medical Journal, 20, 177. https://doi:10.11604/pamj.2015.20.177.4025

- Ho, P. M., Rumsfeld, J. S., Masoudi, F. A., Reese, D., Linder, R., Ahrens, S. \& Magid, D. J. (2006). Effect of medication nonadherence on hospitalization and mortality among patients with diabetes mellitus. Achieve of Internal Medicine, 166(17), 1836-1841. https:// doi:10.1001/archinte.166.17.1836

- Kaiser, A. B., Zhang, N. \& Van der Pluijm, W. (2018). Global prevalence of type 2 diabetes over the next ten years (2018-2028). Diabetes, 67 (Suppl. 1), 202. https://doi.org/10.2337/db18-202-LB

- Krapek, K., King, K., Warren, S. S., George, K. G., Caputo, D. A., Mihelich, K., ... Lubowski, T. J. (2004). Medication adherence and associated hemoglobin A1c in type 2 diabetes. Annals of Pharmacotherapy, 38(9), 1357-1362. https://doi:10.1345/aph.1D612

- Lingam, R., \& Scott, J. (2002). Treatment non-adherence in affective disorders. Acta Psychiatrica Scandinavica, 105(3), 164-172. https://doi:10.1034/j.1600-0447.2002.1 r084.x

- Mikhael, E. M., Hussain, S. A., Shawky, N. \& Hassali, M. A. (2019). Validity and reliability of anti-diabetic medication adherence scale among patients with diabetes in Baghdad, Iraq: a pilot study. BMJ Open Diabetes Research \& Care, 7(1), e000658. https://:doi:10.1136/ bmjdrc-2019-000658

- $\quad$ Musenge, E. M., Michelo, C., Mudenda, B., \& Manankov, A. (2016). Glycaemic Control and Associated Self-Management Behaviours in Diabetic Outpatients: A Hospital Based Observation Study in Lusaka, Zambia. Journal of Diabetes Research, 2016, 1-9. https:// doi:10.1155/2016/7934654
Nguyen, T. M. U., Caze, A. L. \& Cottrell, N. (2014). What are validated self-report adherence scales measuring? a systematic review. British Journal of Clinical Pharmacology, 77(3), 427-445. https:// doi:10.1111/bcp.12194

- Ogurtsova, K., da Rocha Fernandes, J. D., Huang, Y., Linnenkamp, U., Guariguata, L., Cho, N. H. ... Makaroff, L. E. (2017). IDF diabetes atlas: global estimates for the prevalence of diabetes for 2015 and 2040. Diabetes Research and Clinical Practice, 128, 40-50. https:// doi:10.1016/j.diabres.2017.03.024

- Polonsky, W. H. \& Henry, R. R. (2016). Poor medication adherence in type 2 diabetes: recognizing the scope of the problem and its key contributors. Patient Preference and Adherence, 2016, 12991307. https://doi:10.2147/PPA.S106821

- Sarwar, N., Gao, P., Kondapally Seshasai, S. R., Gobin, R., Kaptoge, S. \& Di Angelantonio, E. (2010). The Emerging Risk Factors Collaboration. Diabetes mellitus, fasting blood glucose concentration, and risk of vascular disease: a collaborative meta-analysis of 102 prospective studies. Lancet, 375(9733), 2215-2222. https:// doi.org/10.1016/S0140-6736(10)60484-9

- Schectman, J. M., Nadkarni, M. M. \& Voss, J. D. (2002). The association between diabetes metabolic control and drug adherence in an indigent population. Diabetes Care, 25(6), 1015-1021. https:// doi:10.2337/diacare.25.6.1015

- $\quad$ Sodihardjo-Yuen, F., van Dijk, L., Wensing, M., De Smet, P. A. \& Teichert, M. (2017). Use of pharmacy dispensing data to measure adherence and identify non-adherence with oral hypoglycemic agents. European Journal of Clinical Pharmacology, 73(2), 205-213. https://doi:10.1007/s00228-016-2149-3

- Stirratt, M. J., Dunbar-Jacob, J., Crane, H. M., Simoni, J. M., Czajkowski, S., Hilliardet, M. E. ... Nilsen, W. J. (2015). Self-report measures of medication adherence behavior: recommendations on optimal use. Translational Behavioral Medicine, 5(4), 470-482. https://doi:10.1007/s13142-015-0315-2

- Stolar, M. (2010). Glycemic control and complications in type 2 diabetes mellitus. American Journal of Medicine, 123(Suppl. 3), S3S11. https://doi:10.1016/j.amjmed.2009.12.004

- Whooley, M. A., Avins, A. L., Miranda, J. \& Browner, W. S. (1997). Case-finding instruments for depression. Two questions are as good as many. Journal of General Internal Medicine, 12(7), 439-445. https://doi:10.1046/j.1525-1497.1997.00076.x

Wilke, T., Groth, A., Mueller, S., Reese, D., Linder, R., Ahrens, S. \& Frank Verheyen, F. (2013). How to use pharmacy claims data to measure patient nonadherence? The example of oral diabetics in therapy of type 2 diabetes mellitus. The European Journal of Health Economics, 14(3), 551-568. https://doi:10.1007/s10198012-0410-y 